\title{
O processo das representações sociais na mídia impressa: a bebida alcoólica, o alcoolismo e o leitor em foco
}

\author{
El proceso de las representaciones sociales en la \\ impresión: la bebida alcohólica alcoholismo, y el \\ lector en el foco
}

\section{The process of social representations in print: the alcoholic beverage, alcoholism and the reader in focus}

\author{
Vander Monteiro da Conceição ${ }^{1}$ \\ Silvio Èder Dias da Silva² \\ Jeferson Santos Araújo ${ }^{3}$ \\ Maria Elizabeth Santana ${ }^{4}$ \\ Lucialba Maria Silva dos Santos ${ }^{5}$
}

1 Enfermeiro, Bacharel e Licenciado Pleno em Enfermagem e Obstetrícia pela Faculdade de Enfermagem (FAENF) da Universidade Federal do Pará (UFPA). Especialista em Integralidade da Atenção Oncológica pelo Instituto de Ensino e Pesquisa em Psicologia e Saúde (IEPS). Mestrando em Enfermagem Fundamental pela Escola de Enfermagem de Ribeirão Preto da Universidade de São Paulo. vandervinson@hotmail.com

2 Enfermeiro, Doutor em Enfermagem pela Faculdade de Enfermagem da Universidade Federal de Santa Catarina (UFSC). Professor da Faculdade de Enfermagem da UFPA. silvioeder2003@yahoo.com.br

3 Enfermeiro, Bacharel e Licenciado Pleno em Enfermagem e Obstetrícia pela Faculdade de Enfermagem (FAENF) da Universidade Federal do Pará (UFPA). Especialista Enfermagem do Trabalho pelo Instituto Brasileiro de PósGraduação e Extensão (IBPEX). jeferson-ma@ig.com.br 4 Enfermeira, Doutora em Enfermagem Fundamental pela Escola de Enfermagem de Ribeirão Preto da Universidade de São Paulo. Professora da Faculdade de Enfermagem da UFPA e UEPA. Enfermeira, Doutora em Enfermagem Fundamental pela Escola de Enfermagem de Ribeirão Preto da Universidade de São Paulo. Professora da Faculdade de Enfermagem da UFPA e UEPA. betemary@terra.com.br 5 Enfermeira, Bacharel e Licenciado Pleno em Enfermagem e Obstetrícia pela Faculdade de Enfermagem (FAENF) da Universidade Federal do Pará (UFPA). Especialista em Integralidade da Atenção Oncológica pelo Instituto de Ensino e Pesquisa em Psicologia e Saúde (IEPS). Mestrando em Enfermagem pela FAENF/UFPA. lucialbasilva@ hotmail.com

\section{RESUMO}

A pesquisa tem como objeto de estudo as representações sociais da mídia impressa sobre a bebida alcoólica, para se identificar tal representação teve-se como objetivos identificar artigos publicados nas revistas Veja® e Istoé® no período de 2005 a 2010 e, analisar as representações sociais produzidas por tais publicações sobre a bebida alcoólica. O conteúdo para analise do estudo emergiu da seleção de matérias jornalísticas contidas em 67 reportagens. O estudo configura-se em uma pesquisa documental associado ao fenômeno conceitual da Teoria das Representações Sociais, e aborda os significados relacionados ao incentivo do consumo da bebida alcoólica os quais foram agrupados por apresentarem em seus conteúdos, informações que despertassem o leitor a provar e/ou aprimorar a forma de como degustar a bebida alcoólica. O estudo contribuiu para a compreensão do papel da mídia frente à sociedade leitora no combate aos problemas de saúde publica relacionado ao consumo excessivo de bebida alcoólica. 
Palavras chave: Imprensa. Alcoolismo. Enfermagem Psiquiátrica.

\section{RESUMEN}

La investigación tiene como objetivo estudiar las representaciones sociales de la impresión sobre el alcohol, para identificar a dicha representación tuvo como objetivo identificar los artículos publicados en revistas Veja® y Isto É® en el periodo 2005 a 2010 y analizar las representaciones sociales producida por este tipo de publicaciones sobre el alcohol. El análisis de contenido para el estudio surgió de la selección de las noticias contenidas en 67 informes. El estudio establece en el documento asociado con el fenómeno de la teoría conceptual de las representaciones sociales, y analiza los significados relacionados con el fomento del consumo de bebidas alcohólicas que se agruparon en su contenido, ya que tenía información de que despertar al lector a probar y / o mejorar la forma en cómo el sabor del licor. El estudio contribuyó a la comprensión del papel del lector los medios de comunicación ante la sociedad en la lucha contra problemas de salud pública relacionados con el consumo excesivo de alcohol.

Palabras clave: Press. El alcoholismo. Enfermería Psiquiátrica.

\section{ABSTRACT}

The research aims to study the social representations of print on alcohol, to identify such representation had as objective to identify articles published in magazines Veja ${ }^{\circledR}$ and Isto É® in the period 2005 to 2010 and analyze the social representations produced by such publications on alcohol. The content analysis for the study emerged from the selection of news stories contained in 67 reports. The study sets up on the document associated with the phenomenon of conceptual theory of social representations, and discusses the meanings related to encouraging the consumption of alcoholic beverages which were grouped in their content because they had information that awaken the reader to prove and / or improve the way how to taste the liquor. The study contributed to understanding the role of the media reader before society in combating public health problems related to excessive consumption of alcohol.

Keywords: Press. Alcoholism. Psychiatric Nursing.

\section{INTRODUÇÃO}

Desde os tempos mais remotos da história da humanidade o contanto com o álcool existiu, pois o desejo de experimentar "coisas" novas faz parte do ser humano. Tal consumo faz-se presente até os dias atuais, pois a sociedade contemporânea nos incita a busca de felicidade e de novos prazeres, porém, a idéia de prazer eterno é falso quando percebe-se que tais sensações são apenas passageiras, logo, jamais poderá ser satisfeita por período integral, mesmo se tivermos condições econômicas para manter seu consumo.

O uso do álcool é cultural, sendo permitido em quase todas as sociedades do mundo. Informações sobre "saber beber com responsabilidade e as consequiências do uso inadequado de álcool”, são insuficientes e não contemplam em sua totalidade a população de maior risco para o consumo, como os adolescentes e adultos jovens ${ }^{(1)}$. 
Ao estabelecer a Política de Atenção Integral aos Usuários de Álcool e outras Drogas em 2003, o Ministério da Saúde do Brasil reconheceu que houve um atraso histórico do Sistema Único de Saúde (SUS) na assunção da responsabilidade pelo enfrentamento de problemas associados ao consumo de álcool e outras drogas. Esse atraso remete a dois aspectos que caracterizam a história das intervenções dos governantes brasileiros na área do alcoolismo e outras drogas: as abordagens, intervenções e políticas foram originadas e predominantemente desenvolvidas no campo da Justiça e da segurança pública; e as dificuldades para o enfrentamento dos problemas associados a consumo de álcool e outras drogas, na agenda da saúde pública ${ }^{(2)}$.

O SUS demorou a adequar-se na atenção aos usuários de álcool, os profissionais da saúde também estiveram neste processo de adequação, pois além de atenderem este tipo de patologia, possuem opiniões pré-estabelecidas sobre o assunto, em muitos momentos pré-conceitos. Este ocorre por falta de conhecimento sobre o assunto, ou mesmo pelo meio sociocultural ao qual o profissional está inserido, cabendo então, o aprofundamento em pesquisas sobre a temática do alcoolismo e posteriormente a divulgação para a comunidade da saúde na tentativa de contribuir na mudança.

A mídia, em suas formas variadas de veiculação de informações sobre o tema, influencia direta ou indiretamente a população que a utiliza, sendo então importante fator que leva o consumo de diversos produtos dentre os quais se têm, vestimentas, acessórios, frases (bordões), hábitos, comportamentos e o consumo de bebidas alcoólicas. Os principais alvos são os adolescentes, que durante $o$ período de desenvolvimento acompanham comportamentos de grupos e consequentemente são ditados ou exaltados pela mídia.

As consequências da mídia tem sido destaque em muitas discussões em diferentes segmentos da sociedade contemporânea, todavia, tal interesse surgiu, realmente, com o desenvolvimento de pesquisas de audiência. Novamente, estudiosos de cultura material têm buscado ampliar mudanças prestando atenção maior no papel da materialidade em formas de mídia específicas e no impacto subsequente sobre a criação da sociabilidade. A crescente globalização desse setor pode ser relacionada ao crescente consumo privado do tipo destacado pelos estudos etnográficos da mídia como cultura material ${ }^{(3)}$.

Pesquisas recentes têm investigado a maneira pela qual a propaganda na mídia, de maneira geral, retrata questões de saúde pública. Tais estudos buscam compreender e descrever várias perspectivas sobre as questões de saúde e meios de comunicação ${ }^{(4)}$.

Além da importância, enquanto meio de propagação de idéias, a mídia torna-se uma fonte de identificação fundamental para os sujeitos ou grupos como forma de localização social de uma opinião pessoal. É interessante ressaltar que a mídia, além de ser uma fonte de formação de crenças e atitudes, também pode representar um contexto específico podendo, portanto, refletir ou influenciar pensamento coletivo em um determinado momento. Dessa forma, os meios de comunicação de massa tornam-se um importante veículo de fortalecimento e difusão de ideologias específicas com grande poder de alcance $^{(5)}$.

Revista Tempus Actas de Saúde Coletiva 203 


\section{OBJETIVO}

Analisar os artigos produzidos pela mídia impressa brasileira sobre a bebida alcoólica, publicado nas revistas de circulação nacional Veja® e Istoé®, no período compreendido entre 2005 a 2010, e a partir de então caracterizar as representações sociais sobre o tema proposto.

\section{METODOLOGIA}

O presente estudo foi do tipo documentaldescritivo, com a abordagem qualitativa e o emprego conceitual do fenômeno da Teoria das Representações Sociais, de acordo com os preceitos de Serge Moscovici e Denise Jodelet.

A pesquisa documental assemelha-se muito a pesquisa bibliográfica. A única diferença entre ambas está na natureza das fontes ${ }^{(6)}$. Enquanto a pesquisa bibliográfica se utiliza fundamentalmente das contribuições dos diversos autores sobre determinado assunto, a pesquisa documental vale-se de materiais que não receberam ainda um tratamento analítico, ou que ainda podem ser reelaborados de acordo com os objetivos da pesquisa.

Em consonância a pesquisa documental, foi aplicada também a pesquisa descritiva, esta que possui como foco principal a descrição das características de determinada população ou fenômeno, ou então o estabelecimento de relações entre variáveis alcançadas por meio do emprego de técnicas padronizadas de coleta de dados, tais como o questionário e a observação sistemática ${ }^{(7)}$.

O emprego da Teoria das Representações Sociais (TRS) está ao fato de que estas representações sociais são produzidas e engendradas no meio social, com a função de contribuir para processos de formação de condutas e de orientação das comunicações sociais ${ }^{(8)}$.

Os fenômenos de representação social são difusos, fugidios, multifacetados, em constante movimento e presentes em inúmeras instâncias da interação social ${ }^{(9)}$. Eles são caracteristicamente construídos no que Moscovici chamou de universos consensuais do pensamento.

O universo consensual nada mais é do que uma criação visível e contínua, permeada com sentido e finalidade, possuindo voz humana de acordo com a existência humana. As pessoas são iguais e livres, com possibilidades de falar em nome do grupo ${ }^{(10)}$. Nele existe a negociação e a aceitação mútua, apóia-se na memória coletiva, no consenso. Aqui o ser humano é a medida de todas as coisas.

A representação social é uma forma característica de conhecimento, de senso comum, que circula na sociedade em que as pessoas estabelecem suas representações em grupos sociais, por meio de diálogos, conceitos e culturas. Trata-se de um conceito da psicologia social, fazendo análise de imagens idealizadas pelo grupo relacionado ao seu cotidiano e das condições que determinam sua prática ${ }^{(11)}$.

Quando se propõe a utilização da TRS em um estudo documental-descritivo, ou seja, em um estudo baseado em discursos apresentados na mídia impressa, relaciona-se ao fato de mesmo existindo o mito da objetividade jornalística, segundo o qual a imprensa deveria ser neutra para que coubesse ao leitor a tarefa 
de interpretação livre dos fatos veiculados, é importante destacar que o objeto analisado e apresentado pela mídia não é a realidade ontológica, mas sim o discurso, o relato de acontecimentos ${ }^{(5)}$.

A mídia, portanto, exerce diariamente uma função mediadora entre o leitor e a realidade, sendo que esta última, antes de ser apresentada, foi lida e interpretada. Sendo assim, a essência do material que realmente chega até os leitores trata-se de certa obra de ficção, uma vez que seu conteúdo é produzido de acordo com os padrões que dão forma e corpo aos fatos, sendo "real" antes de ser apresentado ao seu "consumidor", selecionado, lido e interpretado, ganhando novos sentidos e relevâncias, acrescentandose a esta produção o valor da credibilidade. Assim, esta mídia exerce poder na formação de opiniões e sua interpretação constitui-se em um poderoso instrumento de manipulação da vida social, a ponto de ser qualificado como quarto poder ${ }^{(5)}$.

Os dados para construção do estudo foram obtidos através da busca ativa de informações nas revistas Veja ${ }^{\circledR}$ e Istoé ${ }^{\circledR}$, uma vez que estão acondicionadas e expostas a consulta pública na Biblioteca Estadual da Fundação Cultural do Pará Tancredo Neves (CENTUR) e, para seleção dos artigos, optou-se pelos seguintes critérios: Artigos que tratam da temática álcool ou alcoolismo; Procedência e idioma: artigos nacionais publicados em português; Tipo de publicação: revistas e período de busca entre 2005 a 2010.

Para proceder à análise do material coletado empregou-se a técnica de análise de conteúdo, que pode ser compreendida como a expressão mais comumente utilizada para representar o tratamento dos dados de uma pesquisa qualitativa ${ }^{(12)}$, a qual se desdobra nas seguintes etapas: $1^{\circ}$ - Pré-análise: É o primeiro contato com o conteúdo a ser analisado, favorece a organização do material e a leitura das entrevistas para que haja impregnação das ideias que emergirão. Nesta etapa, retomamse os objetivos iniciais, reformulando-os ou operacionalizando-os frente ao material coletado. $2^{\circ}$ - Exploração do material: Consiste essencialmente na operação de codificação. Esta se realiza na transformação dos dados brutos, visando alcançar o núcleo de compreensão do texto. Posteriormente, se escolhe as regras de contagem que permitem a quantificação. E por último, classifica-se e agrega os dados escolhendo as categorias teóricas ou empíricas que comandaram a especificação dos temas.

Os critérios aplicados permitiram a seleção de 67 artigos somando-se as duas revistas pesquisadas, sendo que a revista $\operatorname{Veja}{ }^{\circledR}$ contribuiu com 22 publicações e a Istoé® com 45. Foi realizado a quantificação por ano, sendo que no ano de 2005 foram encontrados 10 (dez) artigos, 2006 com 16 (dezesseis), 2007 com 20 (vinte), 2008 com seis, 2009 também com seis, 2010 finalizando com nove.

Através da análise, foi possível conhecer e organizar os núcleos de significados relacionados ao incentivo do consumo da bebida alcoólica foram agrupados por apresentarem em seus conteúdos, mesmo que subjetivamente, informações que despertassem o leitor a provar e/ou aprimorar a forma de como degustar a bebida alcoólica, essas representações favoreceram a elaboração das categorias denominadas de: Produzir para consumir: especializando a cerveja; Bebendo ouro: a sofisticação das bebidas alcoólicas; 
Dicas para um bom gole e A nobreza do vinho.

\section{DESENVOLVIMENTO}

\section{Produzir \\ para especializando a cerveja \\ consumir:}

A sociedade difere-se por meio da composição de grupos, que a cada momento vão se afunilando e formando os subgrupos, em que seus continentes são organizados não uniformes. Com relação as suas características socioeconômicas e culturais, pode-se afirmar que alguns subgrupos são o que comem, ouvem, vestem, e bebem, ou seja, são seus poderes aquisitivos frente não as necessidades reais para a manutenção de suas vidas biológicas, são também suas necessidades derivadas do contexto sociocultural ao qual estão inseridos. Logo se comportam de maneira particular condizente as suas realidades.

As várias características dos contextos sociais são constitutivas não apenas da ação e interação, mas também, da produção e recepção de forma simbólica. Assim como acontece realmente com a ação, a produção de formas simbólicas envolve o uso dos recursos disponíveis e a implementação de regras e esquemas de vários tipos por um ou mais indivíduos situados em determinada posição ou posições dentro de um campo ou instituição (13).

Nesta categoria os discursos apreendidos na leitura das reportagens permitiram a elaboração do senso comum entre cinco (7\%) artigos encontrados. Apesar de representarem um percentual reduzido com relação ao total de artigos selecionados, destaca-se que as reportagens aqui categorizadas faziam parte de um grupo das mais importantes da publicação, sendo algumas a temática central do fascículo, ou seja, a reportagem de capa. As representações sociais evidenciadas pelos discursos podem ser observadas nos trechos seguintes:

\begin{abstract}
"A cerveja, consumida com moderação, pode ser um ótimo coadjuvante nos momentos de prazer. Por isso, é a bebida mais popular do mundo. Mas alguns pesquisadores começam a descobrir que, além de boa companheira no lazer, ela pode conquistar também um lugar na prateleira dos produtos com efeito positivo para a saúde." (R1);

“O Brasil, assim como os Estados Unidos, estão produzindo cervejas maravilhosas, tão boas quanto às fabricadas na Bélgica, na Inglaterra e na Alemanha." (R7);

“[...] um mercado em acelerada expansão no Brasil - o das cervejas especiais. Elas se diferenciam das demais por duas características: levam na receita ingredientes de qualidade superior e a maioria é resultado de um processo semi-artesanal, que ocorre em tonéis de pequenas fábricas regionais." (R12).
\end{abstract}

Os artigos permitiram a identificação de uma rede subjetiva de incentivo, em que o consumo moderado da cerveja foi exaltado quando associado ao critério saúde. A primeira reportagem supracitada buscou sua credibilidade por meio das informações que pesquisadores estariam identificando pontos positivos no consumo.

Os trechos permitem ao leitor a compreensão de que a informação seja totalmente verídica, não que esta não o seja, porém é válido ressaltar que uma pesquisa, principalmente quando se trata do efeito de substâncias psicoativas no organismo humano, não são totalmente fidedignas em curto prazo, mesmo que representem pontos positivos, pois apenas serão reais quando contrapostas aos pontos negativos. 
Os artigos também permitiram identificar o incentivo por meio da comparação da bebida alcoólica produzida em território nacional com as produzidas em outros países, em que a produção passa por uma rigorosa fiscalização sanitária e do paladar de seus produtores.

As produções, rústica, artesanal, e orgânica da cerveja foram utilizadas como uma importante estratégia de aproximação ao publico consumidor, semelhante as estratégias utilizadas pelas marcas de roupas de grife, com a confecção de roupas para um grupo "elitizado", as cervejas também acabam selecionar um determinado público mais afortunado.

Apesar da mídia por vezes operar de forma negativa a sociedade, é importante destacar que sua significância é inegável, pois os meios de comunicação auxiliam diversos programas de saúde por meio de informações jornalísticas, ou de campanha publicitárias construídas para tal fim. E necessário também utilizá-la como aliada na prevenção do consumo de álcool e outras drogas para que se possa abrir debate sobre o assunto ${ }^{(14)}$.

A elaboração dos universos consensuais de um grupo confirma suas crenças e suas interpretações a cerca de um determinado tema. As representações advindas de um coletivo corroboram mais do que contradizem a tradição, esta dinâmica gera a familiarização com as informações as quais são percebidas e compreendidas em relação aos encontros e paradigmas prévios ${ }^{(15)}$.

As representações sociais são representações de algo ou alguém, e seu conteúdo específico implicam na percepção diferenciada dentro de membros de uma sociedade, ou de uma para outra ${ }^{(16)}$. Neste contexto então é possível afirmar que uma informação ao mesmo tempo pode resignificar um cotidiano, como pode passar despercebida pelo mesmo. Então, uma propaganda sobre a bebida alcoólica deve não somente chamar atenção, mas dar ou reutilizar um sentido a um conteúdo já existente, incentivando então a realização de uma ação, o beber.

\section{Bebendo ouro: a sofísticação das bebidas alcoólicas}

Para se compreender o senso comum de um grupo social, ou seja, seus comportamentos e atitudes é necessário estudar mais do que os meios de comunicação, como um código a ser decifrado, e considerá-los como formas de pensamento. Não há necessidade de se elaborar uma nova criptografia, e sim desprender o significado mais profundo de um grupo social, pois nesse momento se compreenderá o ser, seus comportamentos e suas atitudes ${ }^{(17)}$.

Uma sociedade não pode ser caracterizada pela reunião de um coletivo de indivíduos em uma hierarquia de poder, ou em uma composição de interesses mútuos. Existem sim os desejos e os interesses, porém, para serem reconhecidos como desejo comum dever obter representações que empreguem a eles sentidos e seus idealizadores se esforcem para que sejam garantidos seus interesses ${ }^{(16)}$.

As representações sociais elaboradas e enfatizadas nesta unidade temática foram associadas ao tema sofisticação com o senso comum de onze $(16,4 \%)$ das reportagens, em que os produtores dos textos buscaram ressaltar questões econômicas para aquisição de alguma bebida em particular, esta não sendo 
a cerveja, uma vez que na unidade anterior descrevemo-las como uma bebida popular, e as bebidas tratadas neste momento correspondem às designadas pela sociedade como as mais seletas do ramo do álcool.

"Depois de uma proibição de 95 anos, o licor supostamente alucinógeno volta aos Estados Unidos [...] O preço? Entre US\$ 50 e US\$ 60 a garrafa." (R 31);

"Bares americanos criam drinques que podem custar mais de 2000 dólares. E há quem os beba." (R 18);

"Ela começou a ser produzida há mais de 400 anos no Brasil, mas só recentemente ganhou uma aura de refinamento." ( $\mathrm{R} 38)$;

"Bebidas tradicionais se sofisticaram, mudaram no sabor e na textura, com a única finalidade de agradar aos paladares exigentes." (R 50).

As abordagens textuais exemplificam a dinâmica do incentivo para o consumo da bebida alcoólica como um meio atrativo de "luxo", como algo de sofisticação, onde as bebidas com o maior valor monetário são conhecidas como a "nata" do ramo do álcool, em que apenas um grupo seleto pode desfrutar de seus sabores.

Além das questões financeiras, foi envolvida na valorização das bebidas a influência que cada uma exerce, algumas por seus altíssimos poderes alucinógenos, em que o autor do artigo buscou o uso deste artifício para convidar o leitor a arriscar-se em um gole do referido produto.

A tradicionalidade esteve também presente nos textos selecionados, podendo ser observado quando os artigos enfocavam as bebidas envelhecidas, ou de produção artesanal, ou mesmo que foram criadas em séculos passados e que se mantêm no mercado até os dias atuais. A chamada ao leitor ocorre quando as reportagens geram um clima de suspense quanto ao sabor, logo instiga o individuo a desvendar o mistério da degustação de tal bebida.

Quando um acontecimento impressiona, sua marca, indelével, é a do afeto sentido no momento do choque ${ }^{(18)}$. Não se trata apenas de rememoração, de reprodução, é o acontecimento com sua repercussão inscrita no ser, presentes doravante como sua dimensão fundamental, fonte dos comportamentos que deixam de ser ajustados ao ambiente social, seus códigos e suas normas.

Dessa forma a subjetividade de um indivíduo são produtos que incorporam a experiência do saber e o fazer dos sujeitos e seus autores, o que modela suas relações, em que a mais banal das atividades é relativa a objetos culturais já inseridos do contexto social, não comparáveis com o mundo real, mas ao social, em que sua distinção é somente uma questão de circunstância $^{(19)}$.

O cognitivo e o subjetivo de um individuo são as representações de suas práticas e atitudes quando inseridos em um meio social, ou seja, é a significação elaborada por um grupo social a respeito das informações que são inseridas em seu meio e como ela é assimilada pelo sujeito receptor, sendo exteriorizada pelos seus discursos e comportamentos (20). As representações sociais advindas deste processo revelam a dimensão plural das associações humanas e a presença das ideias gerais no seio da sociedade, além de indicarem a necessidade do estudo de seu impacto nos atos cotidianos (21). 
As subjetividades identificadas nos textos inferem que as reportagens buscaram de alguma forma despertar o leitor para o consumo. Então, trabalharam questões que instigassem o leitor estabelecendo os sentidos de desafio, ou a sede para se provar algo ainda não degustado. Quando o leitor vai atrás da realização destas sensações pode então, como qualquer outra droga, gerar a dependência, pois se a busca for constante e diária, ele poderá então aumentar a dose ou consumir bebidas com teores alcoólicos mais elevados.

\section{Dicas para um bom gole}

O incentivo do consumo da bebida alcoólica não ocorre somente quando uma pessoa é instigada a beber pela primeira vez, é uma tarefa constante que necessita de ferramentas envolvidas no processo. A adição ao álcool não se inicia no primeiro gole, mas na manutenção do mesmo.

A representação é a reprodução de forma consciente das percepções passadas, ou seja, resultam das experiências (sensações) adquiridas e transformadas em uma existência de certo modo independente desses elementos (22). A impressão que tal fato emprega no indivíduo é um processo em dinâmico, em constante aprimoramento e não uma situação estática. Logo um conceito pode ser resignificado quando reexperimentado por uma pessoa e representar sentidos diferentes ao da primeira experiência.

As idéias associadas nestas unidades tratam da bebida alcoólica de forma natural, como se o seu consumo fosse comum a todos, e o incentivo ocorre nos cuidados que o consumidor deve promover para que o seu produto não perca suas propriedades gustativas. Os três (4\%) seguintes recortes textuais a seguir demonstram tal realidade:

\begin{abstract}
"Pode parecer um detalhe, mas não é. Uma taça apropriada faz toda a diferença na hora de apreciar um bom vinho. Para sentir a diferença, basta experimentar o mesmo vinho servido em três recipientes: uma xícara, um copo de vidro e uma taça de cristal.” (R 20);
\end{abstract}

"Os formatos e os tamanhos dos copos variam de
acordo com a bebida." (R 15);

"Especialistas ouvidos por VEJA dão três sugestões simples para conservar o vinho em casa sem o uso de uma adega.” (R 46).

Os textos acima informam através de seu senso comum que a população de forma geral utiliza a bebida alcoólica, só não explicitada às formas deste consumo. $\mathrm{O}$ fator preocupante identificado foi o tratamento da questão beber, os textos não se referiram como beber e sim como melhor beber, logo o álcool não foi tratado como uma droga que gera dependências, sobretudo como um produto mantenedor da socialização.

É interessante ressaltar que o consumo abusivo da bebida alcoólica tornou-se um problema de saúde pública, assim como o uso do tabaco e das drogas ilícitas. Porém, pouco se tem discutido tal tema em grande escala, ao invés do combate ao uso do álcool as medidas provisórias relativas ao tema apenas regulam formas de produção ou obrigam que esteja visível em qualquer propaganda as frases "se beber não dirija" ou "beba com moderação", mas qual o impacto destas falas na totalidade do marketing que incentiva de diversas formas na sociedade?

Como identificado nas unidades anteriores, $\mathrm{o}$ estímulo ocorre de forma implícita em distintos 
episódios, sempre direcionada a um público que já faz uso do produto alcoólico, ou instiga o uso das estratégias para a suposta melhora do consumo. A sociedade está "cercada" de informações que "bombardeiam" suas subjetividades, e reforçam crenças populares, ou seja, revigoram concepções culturais que podem em algum instante ser prejudiciais a sua saúde.

Os significados empregados às palavras de um discurso, como o de uma revista, não são produzidos apenas por um indivíduo, mas por uma coletividade subjetiva, por seu processar histórico e no desenvolvimento de sua consciência social. Estas representações se transformam por meio de atividades e pensamentos de indivíduos concretos, e assim se subjetivam, ganhando caráter pessoal retornando após para objetividade real do mundo que os cerca, por meio de ações que por eles são desenvolvidas ${ }^{(23)}$.

Para analisar os discursos, é preciso denotálo o de forma complexa o sentido que lhe é peculiar. O primeiro passo é desprender-se de um extenso e eficaz aprendizado que direciona o pesquisador a identificação somente de um conjunto de signos, como significantes que referem a determinados conteúdos, carregando tal ou qual significado, quase sempre escuso. É necessário compreender cada discurso, dentro de um espaço ou num tempo anterior a ele, em que se pode desvelar, intangível, a realidade (24).

Com as diversidades de informações que as revistas transmitem, que impregnam um sentido e posteriormente se auto contradizem o leitor acaba a todo tempo sendo "obrigado" a resignificar conceitos passados para adequar-se ao presente almejando um futuro. Assim, encurralado em um presente de larga complexidade, o indivíduo atomiza-se diante da dificuldade de conceber uma experiência temporal coerente. Resultando em uma fragmentação de suas referências, gerando um amontoado de fragmentos e uma prática da heterogeneidade a esmo ${ }^{(25)}$.

A mídia desde sua criação contribuiu categoricamente para a construção de uma subjetividade nos seres humanos, constantemente associados ao desenvolvimento das sociedades capitalistas, dessa forma é impossível hoje pensar no mundo contemporâneo sem levar em conta o papel da mídia ${ }^{(26)}$.

As representações sociais elaboradas nesta subcategoria são modalidades de conhecimento particular que circulam no cotidiano do leitor tendo como função a comunicação entre indivíduos, criando informações e familiarizando-os com o estranho podendo agregar-se a cultura por meio da ancoragem e objetivação do fato ${ }^{(15)}$.

Os sentidos representados nesta subcategoria nortearam para o sentido de ensinar, mas não o fazer apenas com a necessidade de aprendizado real do outro, mas para o aprimoramento de uma necessidade derivada e que deve ser mantida para a satisfação de terceiros. As dicas para um bom gole, como sugere o título, nada mais é do que a apreensão de uma ação comum um grupo social para o incentivo desta e não para sua ressignificação enquanto uma atividade negativa. 


\section{A nobreza do vinho}

O vinho da uva é um dos mais antigos drinks criados pelo homem, sua produção é tradicional e atualmente é sinônimo de requinte. Seu processo de fabricação é rigorosamente controlado em países europeus, porém tantos detalhes interessam apenas a uma determinada classe social, pois assim como existem uma variedade seleta de vinhos, há também aqueles que não possuem muito primor, mas são consumidos mesmo assim pela maior parte da população, porém com o mesmo simbolismo de nobreza.

A representação social de nobreza está associada a um sistema de valores, de ideias e de práticas em que o indivíduo estabelece uma ordem para guiar-se em seu mundo material e social na tentativa de controlálo ${ }^{(27)}$. Proporciona também a comunicação entre membros de uma comunidade por meio do fornecimento de um código comum aos diversos membros de seu mundo e de seu contexto histórico individual e grupal.

Os seis (9\%) escritos classificados nesta subcategoria representam o vinho com algo nobre, em que o mesmo foi agregado as idéias de saúde, a tradicionalidade e ao despertar de sentimentos. Os excetos a seguir corroboram tais afirmativas:

"Por duas décadas, pesquisadores americanos acompanharam 1800 pessoas com idade entre 55 e 65 anos para investigar a relação entre o consumo do álcool e a expectativa de vida. $O$ resultado é surpreendente: a taxa de mortalidade se mostrou maior entre os abstêmios." (R 3);

"Portugal está em festa. Na cidade de Vila Real, as celebrações começaram na quinta-feira 31 com um recital de música do século XVIII. Em
São João da Pesqueira, a programação prevê a realização de banquetes que reproduzem o ambiente palaciano daquele período. Sessões de cinema, palestras, exposições de fotografias e até um leilão de garrafas antigas prometem consumir $R \$ 2,8$ milhões até domingo. O motivo para tanto fuzuê é etílico. Faz exatamente 250 anos que o vinho do Porto tem nome, sobrenome, certidão de nascimento e comprovante de residência." ( $\mathrm{R}$ 16);

"A Argentina tem o malbec, o Chile a carmenere, Austrália a shiraz, a Borgonha a pinot noir e o Brasil ... Se cada país ou região tem um tipo de uva que marca sua identidade no mundo dos vinhos de qualidade, então o País parece finalmente ter encontrado sua bandeira: nós temos a merlot." (R 51).

O saber científico é constantemente deturpado pela população, logo a informação exposta no primeiro exceto selecionado poderia causar um determinado caos se interpretado de maneira errônea, pois se as pessoas que bebem vivem mais que os abstêmios, o entendimento do leitor poderia afirmar que regrar sua ingesta alcoólica pouco influencia nos seus autocuidados com a saúde.

O alcoolismo não é apenas um transtorno dependente que causa danos apenas no organismo humano, é também uma doença social, em que o indivíduo pode até não agredir seus familiares ou comunidade ao qual está inserido de forma direta, mas as experiências negativas derivadas da situação inicial descrita podem ser muito mais traumatizantes.

As reportagens direcionaram suas representações também para a demonstração de como o vinho estabeleceu e manteve seu lugar entre as bebidas mais famosas e importantes do mundo. O capital gerado por seu comércio permitiu que algumas marcas fossem reconhecidas como as melhores do 
ramo. Os textos vincularam as ideias de poder, de alteridade pelas demais bebidas alcoólicas.

O tratamento particular empregado ao vinho consentiu que o leitor entendesse que a bebida nesta subcategoria discutida não seja apenas um mero drink ingerido comumente, mas um produto de elevado nível socioeconômico, logo saboreá-lo não apenas deglutir um suco fermentado é também tomar para si um pouco da pompa social que a bebida "carrega".

Os trechos reforçam a idéia de que o bom vinho desperta sentimentos de prazer, porém, realizando-se um paralelo com outras drogas é fácil destacar que qualquer substância psicoativa permite sentimentos de paz ou alteridade, logo o vinho por ser também uma droga promoverá o bem estar mental em pouco tempo após a sua ingestão. A busca então por este prazer é indubitavelmente possível de acontecer e consequentemente a adição alcoólica estar instalada.

As representações sociais identificadas neste contexto permitem afirmar que o senso comum neste momento gerou o incentivo para o consumo do vinho por meio de sua simbologia aristocrata. A exaltação de um determinado produto pela mídia favorece que os expectadores possam interpretar de diversas formas o seu conteúdo, mesmo que ele seja objetivo. Qualquer texto produzido por um indivíduo está passível de interpretações, porém o sentido real de uma mensagem é apenas conhecido por seu emissor, logo o impacto gerado no receptor depende dos recursos utilizados por ele para elaborar uma determinada informação.

A mídia uma importante ferramenta para a formação de crenças e atitudes, sobretudo aos dependentes de álcool e outra drogas, pois o meio de comunicação em massa identifica normas sociais e produz ou divulga informações que podem dialeticamente influenciar ou desmotivar o uso de substâncias psicoativas ${ }^{(5)}$. Ela não procura somente vender e/ou legitimar o ideário global, visa também transformar a realidade em um discurso social e hegemônico, difundindo perspectivas formas de se viver transferindo para o mercado controle de demandas coletivas ${ }^{(28)}$.

A ideologia neste caso possui dois sentidos, o positivo e o negativo, o primeiro é uma cosmovisão, ou seja, um conjunto de valores, idéias, ideais e filosofias de uma pessoa ou um grupo social. O segundo sentido corresponde à elaboração de idéias distorcidas, enganadoras e mistificadoras que sustentam relações de dominação (26). Neste estudo adotouse o segundo sentido para compreender as mensagens subliminares de um texto publicado.

A ideologia é a um mero reflexo de determinismos socioeconômicos, em que ao longo da história são perceptíveis suas influências recíprocas entre a economia, a política e a ideologia ${ }^{(29)}$. Representa o ideal de uma sociedade organizada podendo abranger tanto um projeto a ser realizado como uma justificativa de práticas coerentes. Pode ser formulada de forma explicita ou não, com ou sem saliência política e de acordo com as variações do tempo e espaço.

Em qualquer texto, o autor para seduzir o leitor usa de artifícios, quando se trata de textos produzidos pela imprensa a sedução é muito mais contundente, pois o autor não visa apenas escrever, mas vender o que escreve, 
seja para fins lucrativos visíveis ou subjetivos. O estranho costuma se uma atração para o homem, em que ao mesmo tempo intriga, perturba as pessoas e as sociedades, provoca medo, porém quando este fator torna-se familiarizado ao cotidiano transforma-se mais extraordinário e interessante. Neste contexto as representações sociais apreendidas tomam forma e são comunicadas para fazer o mundo cotidiano mais estimulante ${ }^{(15)}$.

Os conhecimentos produzidos pelo senso comum dos trechos selecionados nesta subunidadeestãointricadoscomformasdiversas de pensamento, de saber e comunicação. Sua organização norteiam os dialogo produzido pelos leitores e estruturam suas rotinas. $\mathrm{O}$ senso comum quando produzido orienta a humanidade de acordo com as necessidades do emissor da comunicação, isso se for inserida no cotidiano como verdade e gerar uma relação de confiança ${ }^{(30)}$.

\section{CONCLUSÂO}

Ler e escrever ficaram concebidos não apenas com uma habilidade humana de comunicar-se, mas o escritor pode muito mais que apenas informar, ele é capaz de provocar sentimentos e aflorar sentidos. Já o leitor quando em contato com o texto, não é apenas um mero ator coadjuvante, apreendedor de informações, ele tem um importante papel, o qual não realiza sozinho e sim em conjunto a outros leitores, que por vezes são apresentados a informações que não apenas conduzem a uma prática, porém as reforçam e impregnam e seus cotidianos.

Através do estudo pode-se inferir que a bebida é um produto comum a mesa dos brasileiros, porém para que seja consumido rotineiramente foi necessário que em algum momento na produção, marketing, comercialização e divulgação de pesquisas, houvesse informações objetivas ou subjetivas que incentivassem de forma sublime o seu consumo. Cabe ao leitor conhecer melhor sobre o assunto vinculado a mídia, pois somente com as diversidades de informações obtidas em uma reportagem ele pode então "manobrar" as informações ou ser "manobrado" por elas se for a favor do senso comum produzido.

Entende-se que para o reconhecimento da mídia impressa a cerca do alcoolismo é necessário a realização não apenas de um estudo, mas de uma constante análise, pois se trata de uma representação social, ou seja, um significado dinâmico e constante que hoje é compreendido, mas pode se tornar um desconhecido aos olhos dos pesquisadores.

Os artigos analisados apontaram dicas para o melhor consumo, assim como exaltavam as "melhores" marcas, dasquaiseramsimbolizadas por maior valor. A tradicionalidade da bebida também foi um foco apontado, em que o vinho foi concebido como nobre, pois sua produção é milenar, ou seja, já está inserido no cotidiano a muitos anos, e por meio da reportagem teve seu significado reforçado. A cerveja também foi alvo da discussão, pois os textos relatavam ao leitor que a produção a cada momento ficava mais próxima do consumidor para que o mesmo perceba a preocupação dos fabricantes em agradá-los a qualquer custo.

O estudo serve como base para que os profissionais de saúde possam também conhecer melhor o fenômeno da bebida alcoólica e o alcoolismo. Por meio do presente 
estudo o enfermeiro pode utilizar uma de suas principais ferramentas do cuidado, a educação em saúde, desempenhando um importante papel na promoção da saúde diante de vários aspectos, dentre eles a formação e capacitação dos profissionais de saúde visando à redução da demanda de álcool e drogas no Brasil.

Para se conhecer uma sociedade é necessário compreender que suas experiências são advindas de diversas experiências políticas, econômicas, culturais, psicológicas e biológicas, logo este estudo completou apenas uma de milhares de pesquisas a serem realizadas, para que um dia os fomentos gerados possam realmente acompanhar a realidade de diversas populações, sobretudo a brasileira, que sofre a cada com um novo alcoolista na sociedade.

\section{REFERÊNCIAS}

1 - Brasil MS. Secretaria Executiva. Coordenação Nacional de DST e AIDS. A Política do BRASIL para a Atenção Integral a Usuários de Álcool e outras Drogas. Brasília (DF), 2003.

2 - Machado AR, Miranda PSC. Fragmentos da história da atenção à saúde para usuários de álcool e outras drogas no Brasil: da Justiça à Saúde Pública. Hist. Cienc. SaudeManguinhos, Rio de Janeiro, v. 14, n. 3, set. 2007.

3 - Miller D. Consumo como cultura material. Horiz. Antropol., Porto Alegre, v. 13, n. 28, dez. 2007.

4 - Pinsky I, Pavarino FRV. A apologia do consumo de bebidas alcoólicas e da velocidade no trânsito no Brasil: considerações sobre a propaganda de dois problemas de saúde pública. Rev. Psiquiatr. Rio Gd. Sul, Porto Alegre, v. 29, n. 1, abr. 2007.

5 - Ronzani TM, Fernandes AGB, Gebara CFP, Oliveira AS, Scoralick NN, Lourenço LM. Mídia e drogas: análise documental da mídia escrita brasileira sobre o tema entre 1999 e 2003. Ciênc. saúde coletiva, Rio de Janeiro, v. 14 , n. 5 , dez. 2009.

6 - Gil AC. Métodos e técnicas de pesquisa social. 5 ed. São Paulo: Atlas, 1999.

7 - Figueiredo NMA. Método e metodologia na pesquisa científica. 2 ed. São Paulo: Yendis, 2007.

8 - Moscovici S. A representação social da psicanálise. Rio de Janeiro: Zahar Editores, 1978.

9 - Sá CP. A Construção do objeto de pesquisa em representações sociais. Rio de Janeiro: UERJ, 1998.

10 - Moscovici S. Representações sociais: investigações em psicologia social. Petrópolis: Vozes, 2003.

11 - Jodelet D. Representações sociais: um domínio em expansão. In: Jodelet D. (Org.). As representações sociais. Rio de Janeiro: UERJ, 2001.

12 - Bardim L. Análise de conteúdo. Lisboa: Edições 70, 1977.

13 - Thompson JB. Ideologia e cultura moderna: teoria social e crítica na era dos meios de comunicação de massa. Petrópolis: 
Vozes, 1995.

14 - Noto AR, Baptista MC, Faria ST, Nappo AS, Galduróz JCF, Carlini EA. Drogas e saúde na imprensa brasileira: uma análise de artigos publicados em jornais e revistas. Cad. Saúde Pública, Rio de Janeiro, v. 19, n. 1, fev. 2003.

15 - Spink MJ (Org.). O conhecimento no cotidiano: as representações sociais na perspectiva da psicologia social. São Paulo: Brasiliense, 1995.

16 - Moscovici S. Representações sociais: investigações em psicologia social. Petrópolis: Vozes, 2009.

17 - Geertz C. O saber local: novos ensaios em antropologia interpretativa. Petrópolis: Vozes, 2007.

18 - Jodelet D. Loucuras e representações sociais. Petrópolis: Vozes, 2005.

19 - Sá CP. Memória, imaginário e representações sociais. Rio de Janeiro: Museu da República, 2005.

20 - Silva SÉD. História de vida e representações sociais: desvelando o universo do alcoolismo dos adolescentes. 217p. Tese (Doutorado em Enfermagem) - Programa de Pós-Graduação em Enfermagem, Universidade Federal de Santa Catarina, 2010.

21 - Oliveira MSBS. Representações sociais e sociedades: a contribuição de Serge Moscovici. Rev. bras. Ci. Soc., São Paulo, v. 19, n. 55, jun. 2004.

22 - Paim I. Curso de psicologia. São Paulo: EPU, 1986.
23 - Spink MJP. Psicologia social e saúde: práticas, saberes e sentidos. Petrópolis: Vozes, 2003.

24 - Fischer RMB. Foucault e a análise do discurso em educação. Cad. Pesqui., São Paulo, n. 114, nov. 2001. Disponível em $<$ http://www.scielo.br/scielo.php?script=sci_ arttext\&pid=S0100-15742001000300009\&ln $\mathrm{g}=\mathrm{pt \& nrm=iso>}$. acessos em 24 jun. 2011. doi: 10.1590/S0100-15742001000300009.

25 - Pena F. Subjetividade midiática: tempo e memória no discurso das biografias contemporâneas. Psicol. clin., Rio de Janeiro, v. 19, n. 1, 2007.

26 - Guareschi PA. Os construtores de informação: meios de comunicação, ideologia e ética. Petrópolis: Vozes, 2000.

27 - Flick U. Introdução a pesquisa qualitativa. Porto Alegre: Artmed, 2009.

28 - Moraes D. O capital da mídia na lógica da globalização. In: Moraes D. (Org.), Por uma outra comunicação: mídia, mundialização cultural e poder. $3^{\text {a }}$ ed., Rio de Janeiro, Record, 2005

29 - Reis EP. O Estado Nacional como Ideologia: o caso brasileiro. Estudos Históricos. Rio de janeiro. vol. 1. n. 2, jan./jun. 1988.

30-OliveiraD, Campos PHF. Representações sociais: uma teoria sem fronteiras. Rio de Janeiro: Museu da República, 2005.

Artigo apresentado em 01/02/2012 Artigo aprovado em 25/02/2012 Artigo publicado no sistema em 17/04/2012 